\title{
METODE MARKETING MIX DAN ANALISIS SWOT DALAM PENYUSUNAN STRATEGI BERSAING PADA IKM KERIPIK TEMPE AYUDY
}

\section{MARKETING METHODS AND SWOT ANALYSIS IN THE COMPETITIVENESS OF COMPETITIVE STRATEGIES IN AYUDY TEMPE CREATER CHIPS}

\author{
Wahyu Maulana \\ Universitas Madura \\ Email: revelation10greats@gmail.com \\ Abd. Jamali \\ Universitas Madura \\ Email: james69zee@icloud.com
}

\begin{abstract}
ABSTRAK
Industri kecil menengah (IKM) merupakan salah satu sektor riil yang menjadi favorit masyarakat untuk bersaing menghasilkan keuntungan yang sebesarbesarnya. Sektor ini juga menjadi landasan yang kuat bagi pemerintah daerah dalam mengembangkan perekonomian daerah yang mandiri. Hal inilah yang menjadi alasan banyaknya IKM yang bermunculan dan didominasi oleh kaum milenial. Tujuan dari penelitian ini adalah untuk mengetahui strategi bersaing dengan metode bauran pemasaran dan analisis SWOT pada salah satu IKM keripik tempe. Jenis penelitian kualitatif dan wawancara langsung merupakan hal-hal yang digunakan dalam penelitian ini. Hasil penelitian menunjukkan bahwa posisi IKM Ayudy berada pada kuadran I pada analisis SWOT dimana strategi yang tepat untuk bersaing adalah dengan menggunakan strategi agresif. Ayudy IKM akan memanfaatkan peluang bisnis yang terbuka dengan fokus pada kekuatan produknya. Strategi bersaing terbagi dalam bauran pemasaran dimana penerapannya meliputi strategi produk dengan melakukan produk inovatif, hal ini dirasa tepat karena untuk mengatasi kejenuhan konsumen agar konsumen tetap nyaman dengan produk dari IKM Ayudy; strategi penetapan harga dilakukan dengan menerapkan harga grosir, hal ini dimaksudkan untuk memudahkan penjualan secara cepat; strategi lokasi dengan membuka gerai penjualan yang ditujukan langsung kepada konsumen terutama yang berada jauh dari rumah produksi; dan tentunya strategi promosi melalui media sosial yang membuat produk lebih dikenal dan berdampak pada peningkatan penjualan.
\end{abstract}

Kata Kunci: bauran pemasaran, analisis swot dan strategi bersaing 
Medium small industry (IKM) is one of the real sectors which is a favorite of the public to compete in producing maximum profits. This sector is also a strong foundation for regional governments in developing an independent regional economy. This is the reason for the many SMIs that have sprung up and are dominated by millennials. The purpose of this study was to determine the competitive strategy using the marketing mix method and SWOT analysis on one of the tempe chips SMIs. This type of qualitative research and direct interviews are things that are used in this study. The results showed that the position of IKM Ayudy was in the quadrant I in the SWOT analysis where the right strategy to compete was to use an aggressive strategy. Ayudy IKM will take advantage of open business opportunities by focusing on the strength of its products. The competitive strategy is divided into marketing mix where its application includes a product strategy by doing innovative products, this is considered appropriate because it is to overcome boredom in consumers so that consumers remain comfortable with the product from the IKM Ayudy; pricing strategy is done by implementing wholesale prices, this is intended to facilitate sales quickly; location strategy by opening sales outlets directly aimed at consumers especially those located far from production houses; and of course promotional strategies through social media that make products more known and have an impact on increasing sales.

Keywords: markeing mix, swot analysis and competitive strategy

\section{PENDAHULUAN}

Keinginan pemerintah pusat untuk mengembangkan UMKM sejalan dengan kebutuhan masyarakat di kalangan menengah ke bawah untuk menjadi seorang wirausahawan. Hal ini tidak terlepas sulitnya mencari "pekerjaan" di tengah membludaknya para sarjana muda di berbagai latar belakang bidang keilmuwan. Pernyataan dari PBB mengatakan untuk menjadi negara yang berkembang setidaknya mempunyai $2 \%$ wirausahawan dari populasi penduduknya, dimana hal ini menjadi sebuah kabar gembira sekaligus warning bagi pemerintah mengingat jumlah wirausahawan di Indonesia telah mencapai 3,1\% atau sekitar 26,4 juta (BPS, 2016). Angka tersebut menandakan angka capaian yang melampaui dari syarat yang telah ditentukan oleh PBB namun disisi lain adalah angka tersebut menempatkan Indonesia jauh tertinggal di kawasan negara Asean seperti Singapura (7\%), Malaysia (5\%), Thailand (4,5\%) dan Vietnam (3,25\%). Minimnya keberadaan UMKM menandakan belum kokohnya fundamental perekonomian Indonesia, karena sudah tidak diragukan bahwa UMKM dapat menjadi penggerak roda perekonomian (Sudaryanto et, al, 2013) serta memberikan dampak besar bagi masyarakat seperti menciptakan lapangan kerja sehingga menyerap banyak tenaga kerja (Sudaryanto, 2011). Hal ini semakin diperkuat dengan data penerimaan untuk negara sebesar $55,56 \%$ melalui pemasukan PDB (produk domestic bruto) melalui pembayaran pajak (Saputro $d k k, 2010)$.

Kondisi inilah yang menjadi salah satu penyebab banyaknya bermunculan para IKM ataupun UMKM di Indonesia. Hal ini yang menjadi perhatian khusus karena masih banyak bentuk usaha yang belum memahami kondisi internal maupun eksternal mereka sehingga banyak kejadian yang menyebabkan posisi usaha IKM ataupun UMKM ini hanya bersifat sementara. Hal ini berdasarkan hasil penelitian yang dilakukan oleh Ramadhan dan Sofiyah (2013), dimana perusahaan haruslah memperhatikan kondisi lingkungan internal dan eksternal mereka untuk keberlangsungan hidup usaha mereka kedepannya. Manajemen perusahaan haruslah mempunyai strategi yang memadai agar visi, misi serta tujuan perusahaan tercapai dan salah satu alat analisis yang bisa digunakan adalah analisis SWOT (Pearce dan Robinson, 2013).

Selain memonitoring strategi manajemen melalui analisis SWOT, diperlukan juga yang namanya strategi pemasaran yang dipergunakan untuk meningkatkan volume penjualan. Dalam hal ini strategi yang biasa digunakan adalah strategi bauran pemasaran. Marketing 
mix merupakan kombinasi straegi dari berbagai kegiatan pemasaran sebagai langkah konkrit dan maksimal dalam menemukan formula baru yang memuaskan, dimana terdiri dari 4P dan ditambah menjadi 3P untuk perusahaan jasa yang saling berkaitan satu sama lainnya (Srisusilawati, 2017). Namun, strategi ini tidaklah cukup dimana hal ini sesuai dengan hasil penelitian yang dilakukan oleh Purwanti (2012) yang menghasilkan hasil penelitian secara parsial tidak ada pengaruh antara strategi pemasaran terhadap perkembangan suatu usaha. Berikut merupakan beberapa penelitian yang berkaitan dengan permasalahan di atas yang menggunakan alat analisis yang berbeda dengan alat analisis yang digunakan dalam penelitian ini, diantaranya : penelitian yang dilakukan oleh Dalfa et, al (2018); Umar (2012); Abidin (2017); serta Anggraeni et, al (2017)

Berangkat dari fenomena dan gap research di atas, maka peneliti melakukan penelitan dengan judul Metode Marketing Mix Dan Analisis SWOT Dalam Penyusunan Strategi Bersaing Pada IKM Keripik Tempe Ayudy

Menurut Galavan (2014), analisis SWOT adalah analisis yang digunakan berdasarkan kondisi pasar dan keadaan publik melalui strategi yang efektif dimana analisis ini menggunakan kondisi internal dan eksternal perusahaan. Analisis SWOT merupakan alat bantu bagi perusahaan untuk membuat strategi yang tepat guna mencapai visi dan misi perusahaan dengan melakukan sebuah identifikasi kondisi internal dan eksternal perusahaan (Rangkuti, 2014). Berikut di bawah ini adalah matrik SWOT yang terdiri dari 4 (empat) kuadaran, diantaranya :

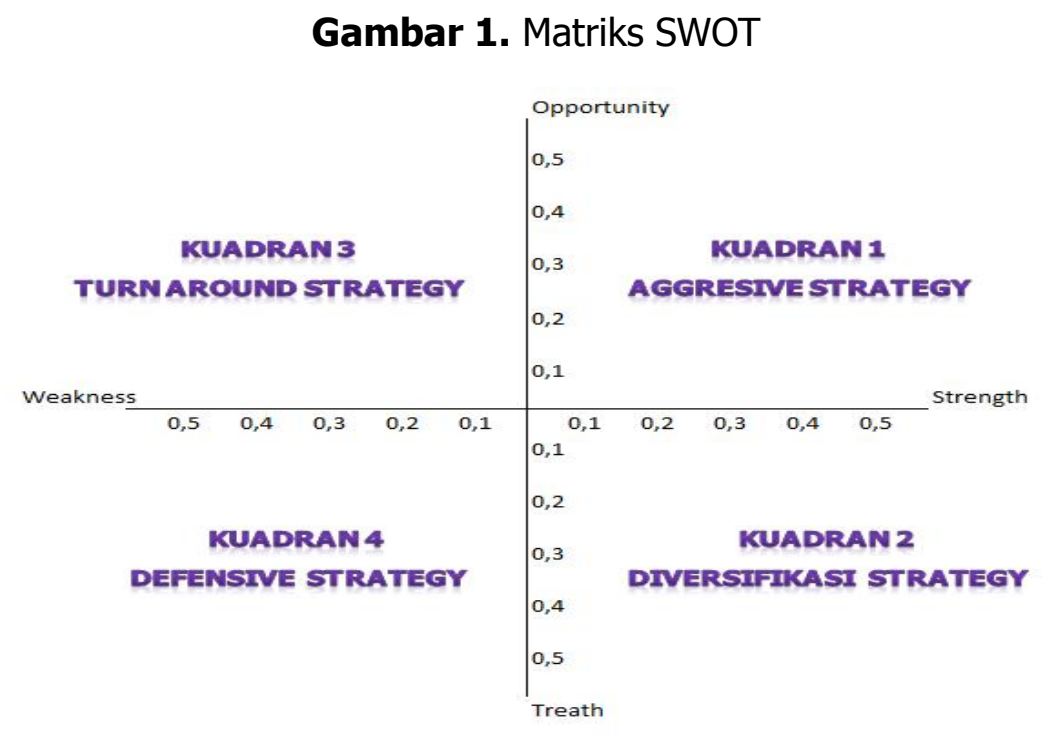

Marketing mix merupakan penyaluran dan costumer value kepada pasar, yang terdiri dari 4 (empat) komponen penting diantaranya : produk, harga, lokasi dan promosi (Kotler dan Keller, 2012). Menurut Kotler dan Amstrong (2012), produk merupakan barang yang ditawarkan kepada konsumen agar dibeli dan menjadi kepuasan terhadap konsumennya; harga adalah angka yang dikeluarkan oleh konsumen untuk mendapatkan sebuah produk yang diinginkannya; lokasi meliputi aktivitas yang dilakukan oleh perusahaan dalam memproduksi barang yang akan dipasarkan; serta promosi adalah aktivitas memperkenalkan produk jualannya kepada konsumen agar terbujuk dan berkeinginan untuk membeli produk tersebut (Tjahjono dan Brahmana, 2013)

\section{METODE PENELITIAN}

Untuk memperoleh data internal dan eksternal IKM Ayudy ini, peneliti menggunakan wawancara yang ditujukan kepada owner IKM Ayudy, pakar/ ahli yang berkompeten di 
bidangnya, para konsumen dan pesaing. Sumber data berupa dokumentasi dan gambaran umum yang merupakan kumpulan data tentang IKM Ayudy itu sendiri dan perusahaan sejenis lainnya (pesaing). Jenis penelitian ini adalah kualitatif melalui validitas dengan metode triangulasi sumber banyak dan reliabilitas. Dimana sumber tersebut berasal dari hasil wawancara dan dokumentasi yang diperoleh dari IKM Ayudy dan perusahaan sejenis lainnya. Menurut Kuncoro (2013), terdapat 2 (dua) macam dalam metode triangulasi data yakni triangulasi dengan sumber banyak (multiple sources) dan triangulasi dengan teknik banyak (multiple methods). Menurut Sugiyono (2013), reliabilitas merupakan tingkat konsistensi dan stabilitas sebuah data. Sebuah data dikatakan reliable jika informasi yang disampaikan oleh banyak sumber mempunyai hasil dengan tingkat konsistensi dan ketetapan yang baik sehingga membuat sebuah hasil penelitian menjadi lebih akurat (Sujarweni, 2014). Teknik analisa data yang digunakan adalah metode reduksi data dimana peneliti mengkombinasikan dan menyelaraskan data yang ada menjadi sebuah tulisan yang dapat dianalisis. Mereduksi data adalah fokus pada hal yang penting dan pokok pembahasan, merangkum, dan mencari pola serta tema pembahasan (Sugiyono, 2014). Adapun tahapan yang dilakukan pada penelitian ini diantaranya : 1. Kumpulkan data sebanyak-banyaknya; 2. Triangulasi data; 3. Analisis marketing mix, 4. Analisis SWOT; 5. Olah data melalui analisis SWOT sehingga tercipta marketing mix yang baru; 6 . Menyusun strategi bersaing bagi IKM Ayudy; dan 7. Menyimpulkan dan memberi saran

\section{HASIL DAN PEMBAHASAN}

Data dari IKM Ayudy yang telah dikumpulkan dan telah dilakukan analisis secara mendalam mengenani beberapa faktor baik yang merupakan faktor internal dan eksternal IKM dalam menjalankan usahanya yang kemudian akan digunakan sebagai faktor strategi IKM yang nantinya akan di analisis dengan menggunakan analisis SWOT yang hasilnya akan digunakan sebagai bahan untuk menentukan strategi bersaing dalam persaingan bisnis yang sifatnya saat ini sangat terbuka. Dimana strategi bersaing ini nantinya akan di analisis dengan menggunakan marketing mix yang meliputi terhadap produk inovatif yang lebih menarik perhatian konsumen, harga yang lebih bersahabat dengan konsumen, promosi yang lebih menarik perhatian konsumen hingga tempat atau lokasi penjualan yang lebih dekat dengan konsumen sehingga hal ini dapat lebih mempermudah konsumen untuk menjangkau produk IKM Ayudy nantinya dan hal ini menjadi salah satu faktor kesuksesan IKM dalam memperoleh keuntungan yang maksimal 
Berikut ini merupakan tabel IFAS (internal factor analysis summary), berikut hasil dan penjelasannya :

Tabel 1. Penentuan IFAS

\begin{tabular}{|c|c|c|c|c|c|}
\hline \multicolumn{6}{|c|}{ Internal factor analysis summary (IFAS) } \\
\hline & & Faktor strategis & Bobot & Rating & Skor \\
\hline \multirow{9}{*}{ 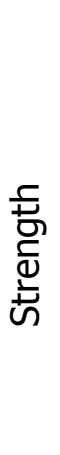 } & 1 & Kemasan memenuhi standar & 0.025 & 3 & 0.075 \\
\hline & 2 & Produk berlegalitas (PIRT) & 0.025 & 4 & 0.100 \\
\hline & 3 & Pelayanan yang ramah & 0.025 & 4 & 0.100 \\
\hline & 4 & Harga ekonomis & 0.100 & 5 & 0.500 \\
\hline & 5 & Produk mudah ditemui & 0.075 & 5 & 0.375 \\
\hline & 6 & Bahan baku mudah diperoleh & 0.050 & 4 & 0.200 \\
\hline & 7 & Volume penjualan meningkat & 0.025 & 3 & 0.075 \\
\hline & 8 & Rasa menggugah selera & 0.050 & 4 & 0.200 \\
\hline & 9 & Produk tanpa bahan pengawet & 0.100 & 5 & 0.500 \\
\hline \multirow{12}{*}{$\begin{array}{l}\mathscr{U} \\
\frac{\mathscr{D}}{\mathbb{J}} \\
\stackrel{\mathbb{D}}{3}\end{array}$} & 10 & Modal kuat karena usaha milik keluarga & 0.025 & 4 & 0.100 \\
\hline & & Sub Total & & & 2.225 \\
\hline & & Faktor strategis & Bobot & Rating & Skor \\
\hline & 1 & Latar pendidikan dan pengalaman masih rendah & 0.025 & 3 & 0.075 \\
\hline & 2 & Bentuk promosi belum beragam & 0.075 & 4 & 0.300 \\
\hline & 3 & Standar alat produksi masih minim & 0.050 & 3 & 0.150 \\
\hline & 4 & Design/ logo produk kurang menarik & 0.075 & 3 & 0.225 \\
\hline & 5 & Produk tidak tahan lama & 0.100 & 5 & 0.500 \\
\hline & 6 & Produk kurang variatif & 0.125 & 4 & 0.500 \\
\hline & 7 & Jarak distribusi tergolong jauh & 0.050 & 3 & 0.150 \\
\hline & & Sub Total & & & 1.900 \\
\hline & & Total & 1 & & 0.325 \\
\hline
\end{tabular}

Sumber : data diolah (2020)

Pada tabel IFAS di atas, penentuan angka pada bobot serta rating dilakukan oleh para informan yang dilanjutkan dengan dianalisis oleh peneliti disesuaikan dengan kondisi obyek penelitian yakni IKM Ayudy. Faktor strategis dari indikator strength dan weakness tersebut diperoleh dari hasil wawancara dengan informan dalam hal ini diantaranya adalah owner dari IKM Ayudy itu sendiri, pakar/ ahli yang berkompeten di bidangnya serta konsumen tanpa terkecuali. Hasil skor dalam tabel IFAS di atas diperoleh dari hasil perkalian yang bersumber dari bobot di setiap indikatornya dengan rating di setiap indikator pengukuran dimana hasil keseluruhan dari perkalian tersebut dijumlahkan sehingga menjadi sub total skor dan selisih setiap sub total dari indikator strength dan weakness menjadi total dari IFAS itu sendiri. Nilai strength dengan total skor 2.225 yang terdiri dari beberapa faktor strategis diantaranya produk, packing, pelayanan, harga, bahan baku, penjualan hingga manajemen IKM itu sendiri pada tabel IFAS ini menunjukkan bahwa indikator ini mempunyai nilai yang lebih besar 0,325 jika dibandingkan dengan nilai weakness dengan total skor 1.900 yang terdiri dari beberapa faktor startegis diantaranya promosi, alat produksi, design, produk, manajemen hingga tempat atau lokasi penjualan yang dimiliki oleh IKM Ayudy tersebut.

Selanjutnya, di bawah ini merupakan kumpulan beberapa faktor strategis eksternal IKM yang telah dirangkum oleh peneliti dalam melakukan penelitian ini. Berikut merupakan 
tabel EFAS (external factor analysis summary) pada IKM Ayudy, berikut hasil dan penjelasannya :

Tabel 2. Penentuan EFAS

\section{External factor analysis summary (EFAS)}

\begin{tabular}{|c|c|c|c|c|c|}
\hline & & Faktor strategis & Bobot & Rating & Skor \\
\hline & 1 & Loyalitas konsumen yang tinggi & 0.100 & 5 & 0.500 \\
\hline & 2 & Segmentasi pasar luas & 0.100 & 4 & 0.400 \\
\hline 营 & 3 & Distribusi penjualan tepat waktu & 0.050 & 3 & 0.150 \\
\hline$\frac{Z}{0}$ & 4 & Kerjasama dengan Dinas Koperasi dan UKM untuk promosi & 0.025 & 3 & 0.075 \\
\hline 응 & 5 & Produk demand yang banyak & 0.150 & 5 & 0.750 \\
\hline & 6 & Kerjasama dengan distributor untuk penjualan & 0.050 & 4 & 0.200 \\
\hline & 7 & Adanya peralatan canggih untuk proses produksi & 0.025 & 3 & 0.075 \\
\hline & & Sub Total & & & 2.150 \\
\hline & & Faktor strategis & Bobot & Rating & Skor \\
\hline & 1 & Pesaing dengan produk serupa & 0.150 & 5 & 0.750 \\
\hline & 2 & Selera pasar berubah & 0.075 & 4 & 0.300 \\
\hline F & 3 & Sulit mendapatkan bahan baku berkualitas & 0.075 & 3 & 0.225 \\
\hline$\stackrel{\square}{\mathbb{d}}$ & 4 & Persaingan harga & 0.100 & 4 & 0.400 \\
\hline & 5 & Dampak perekonomian terhadap daya beli konsumen & 0.025 & 2 & 0.050 \\
\hline & 6 & Regulasi mendapatkan BPOM yang rumit & 0.025 & 2 & 0.050 \\
\hline & 7 & Laba berkurang akibat biaya produksi melonjak & 0.050 & 3 & 0.150 \\
\hline & & Sub Total & & & 1.925 \\
\hline & & Total & 1 & & 0.225 \\
\hline
\end{tabular}

Sumber : data diolah (2020)

Pada tabel EFAS di atas, penentuan angka pada bobot serta rating dilakukan oleh para informan yang dilanjutkan dengan dianalisis oleh peneliti disesuaikan dengan kondisi obyek penelitian yakni IKM Ayudy. Faktor strategis dari indikator opportunity dan treath tersebut diperoleh dari hasil wawancara dengan informan dalam hal ini diantaranya adalah pakar/ ahli yang berkompeten di bidangnya, pesaing dengan usaha yang sejenis, calon konsumen serta konsumen produk IKM Ayudy itu sendiri. Hasil skor dalam tabel EFAS di atas diperoleh dari hasil perkalian yang bersumber dari bobot di setiap indikatornya dengan rating di setiap indikator pengukuran dimana hasil keseluruhan dari perkalian tersebut dijumlahkan sehingga menjadi sub total skor dan selisih setiap sub total dari indikator opportunity dan treath menjadi total dari EFAS itu sendiri. Nilai opprtunity dengan total skor 2.150 yang terdiri dari beberapa faktor strategis diantaranya loyalitas konsumen, segmentasi pasar, distribusi penjualan, relasi atau kerjasama, permintaan akan produk hingga peralatan produksi pada tabel EFAS ini menunjukkan bahwa indikator ini mempunyai nilai yang lebih besar 0,225 jika dibandingkan dengan nilai treath dengan total skor 1.925 yang terdiri dari beberapa faktor strategis diantaranya persaingan produk dan harga, selera konsumen, bahan baku berkualitas, daya beli konsumen, regulasi pemerintah hingga perolehan keuntungan IKM yang dimiliki oleh IKM Ayudy tersebut.

Dari hasil total perhitungan faktor strategis IKM baik secara IFAS dan EFAS yang telah dilakukan analisis perhitungan di atas, maka hasil perhitungan tersebut akan dikonversi ke dalam bentuk matriks dengan keempat indikator SWOT tersebut. Dimana hal ini dilakukan untuk mengetahui posisi IKM pada matriks SWOT dan nantinya akan diketahui pula akan 
strategi apa yang tepat untuk IKM Ayudy kedepan. Berikut merupakan matriks yang dimaksud :

Gambar 2. Matriks SWOT IKM Ayudy

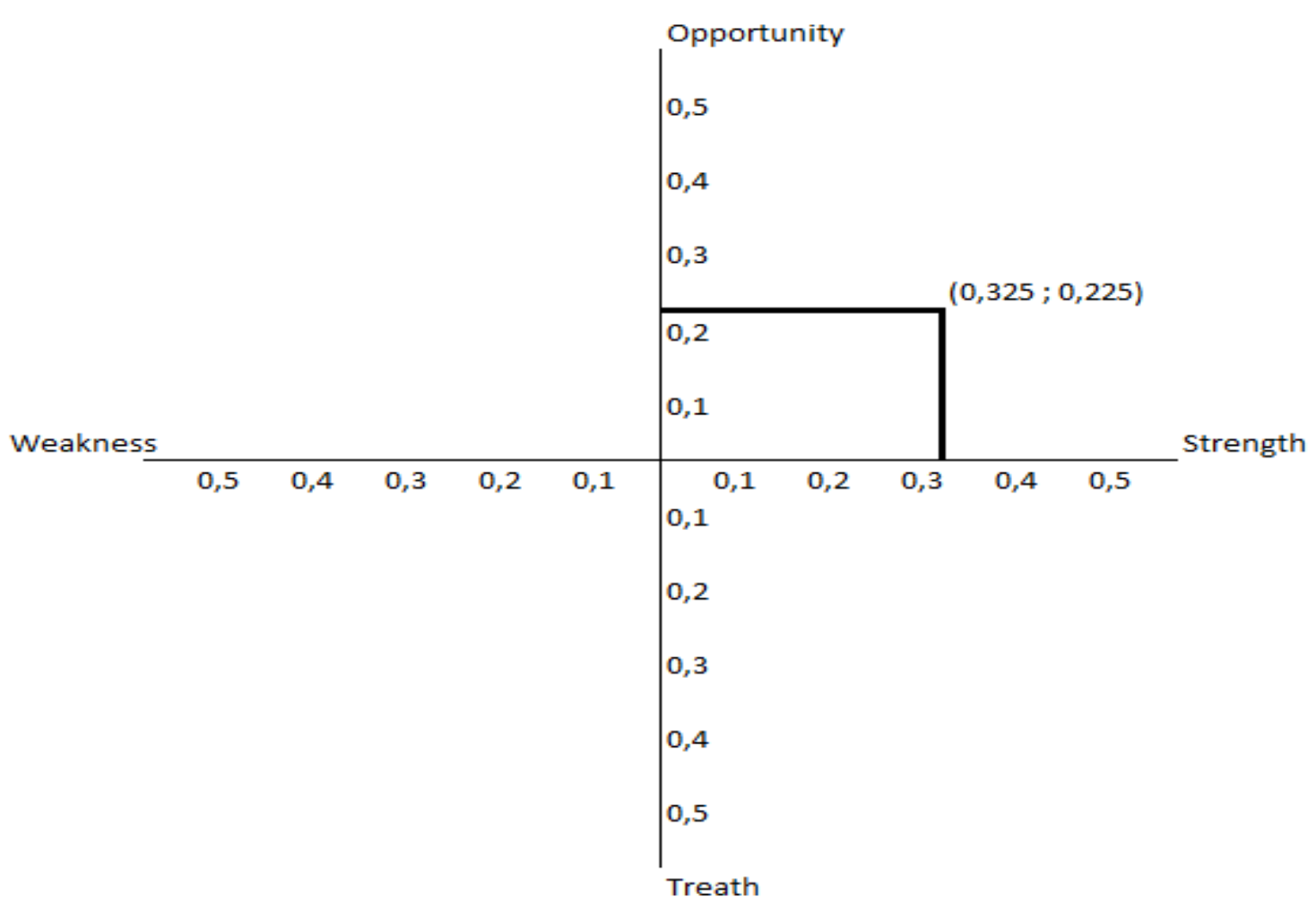

Gambar di atas menggambarkan posisi IKM Ayudy berada pada kuadran I yaitu terbukanya peluang yang begitu luas untuk menjadikan produk IKM Ayudy yang berupa keripik tempe ini lebih dikenal oleh masyarakat dengan memanfaatkan kekuatan produk yang dimilikinya. Fokus strategi pada kuadran I ini merupakan aggressive strategy dimana strategi ini memanfaatkan peluang yang ada dengan terus mendorong produknya agar lebih dikenal yang akan berdampak kepada memaksimalkan keuntungan (Rangkuti, 2014). Peneliti dalam penelitian ini akan berfokus kepada memanfaatkan peluang pada pasar dengan terus memaksimalkan kekuatan internal IKM.

IKM Ayudy telah mengetahui posisi usaha dilihat dari matriks SWOT yakni berada pada kuadran I dimana strategi yang tepat adalah aggressive strategy. Strategi ini digunakan untu memanfaatkan peluang dengan kekuatan yang dimilikinya. Adapun penyusunan strategi pada IKM Ayudy agar bisa bersaing dengan perusahaan sejenis, diantaranya : 
Tabel 3. Simpulan dari segi strength dan opportunity IKM Ayudy

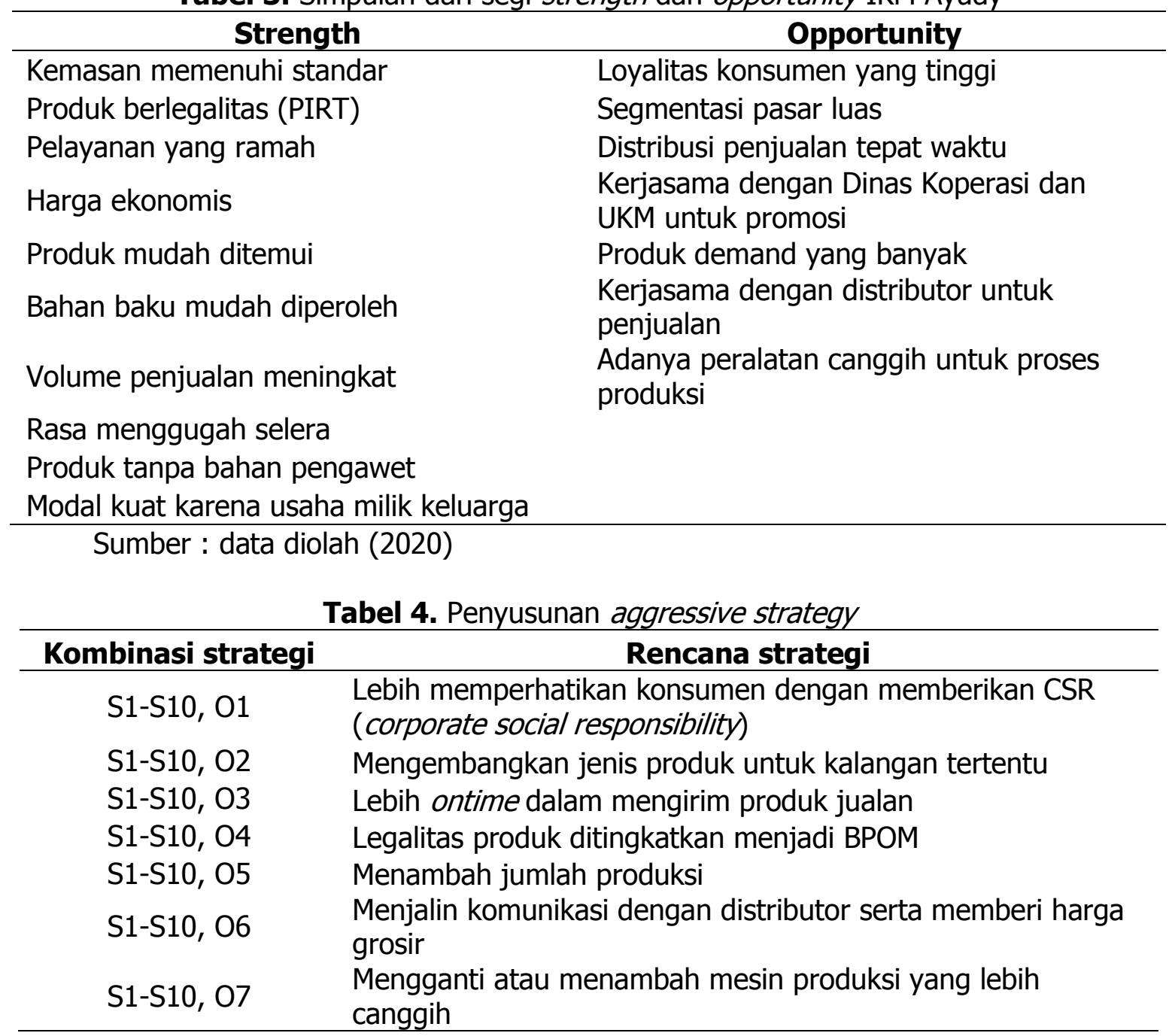

Sumber : data diolah (2020) 
Adapun pada table 5 merupakan rencana strategi marketing mix pada IKM Ayudy, diantaranya :

Tabel 5. Rencana strategi marketing mix

\begin{tabular}{|c|c|c|}
\hline Faktor & Strategi sebelumnya & Rencana strategi \\
\hline Product & $\begin{array}{l}\text { Jenis produk tunggal baik dari segi } \\
\text { kemasan, rasa dan ukuran }\end{array}$ & $\begin{array}{l}\text { Mengembangkan varian produk baik dari } \\
\text { segi rasa, ukuran dan kemasan } \\
\text { Membuat produk inovatif }\end{array}$ \\
\hline Price & $\begin{array}{l}\text { Harga mengikuti jenis produk, } \\
\text { yaitu harga tunggal Rp 5.000,- per } \\
\text { produk }\end{array}$ & $\begin{array}{l}\text { Menciptakan produk baru dengan berbagai } \\
\text { macam harga }\end{array}$ \\
\hline & Penjualan langsung ke toko & $\begin{array}{l}\text { Ada harga grosir khusus untuk distributor } \\
\text { Membuka gerai khusus untuk penjualan } \\
\text { yang lokasinya dekat dengan panqsa pasar }\end{array}$ \\
\hline Place & $\begin{array}{l}\text { Konsumen datang langsung ke } \\
\text { rumah produksi }\end{array}$ & $\begin{array}{l}\text { Lokasi penjualan menambah ke ranah } \\
\text { digitalisasi sehingga konsumen bisa pesan } \\
\text { secara online }\end{array}$ \\
\hline & Penjualan melalui mulut ke mulut & $\begin{array}{l}\text { Menambah akun di media sosial untuk } \\
\text { memasarkan produk }\end{array}$ \\
\hline Her & $\begin{array}{l}\text { Media sosial yang digunakan } \\
\text { belum beragam }\end{array}$ & $\begin{array}{l}\text { Bergabung dengan e-commerce ternama } \\
\text { dan dikenal banyak kaum milenial }\end{array}$ \\
\hline
\end{tabular}

Sumber : data diolah (2020)

Berdasarkan rencana strategi yang telah ditetapkan oleh IKM Ayudy pada tabel di atas, ini merupakan langkah yang dirasa tepat untuk memenangkan persaingan. Tidak hanya itu, hal ini juga untuk membuat konsumen makin loyal terhadap produk IKM Ayudy tersebut. Selain itu, rencana strategi ini dibuat untuk membuat posisi IKM Ayudy makin kuat dan menutupi kelemahan yang ada sebelumnya sehingga membuka peluang semakin terbuka dan mengurangi beberapa ancaman yang menjadi "hantu" bagi IKM Ayudy secara khusus dan bagi IKM sejenis lainnya secara umumnya. Secara keseluruhan, dengan adanya rencana strategi yang berangkat dari hasil analisis marketing mix ini tujuannya ke arah yang lebih baik lagi agar perolehan keuntungan IKM semakin meningkat.

\section{KESIMPULAN}

Dari pembahasan di atas, peneliti dapat menyimpulkan berdasarkan hasil analisis menggunakan SWOT menunjukkan bahwa IKM Ayudy dengan produk keripik tempenya berada di kuadran I dengan artian IKM diharapkan melakukan aggressive strategy untuk lebih menjadikan IKM ini lebih maju dan berkembang. Strategi ini menandakan bahwa IKM ini haruslah memanfaatkan kekuatan yang dimilikinya dengan melihat peluang pasar yang terbuka sehingga IKM ini dapat memaksimalkan keuntungannya. Adapun penyusunan strategi dalam aggressive strategy ini diantaranya : IKM diharapkan memberikan CSR sebagai bentuk perhatian terhadap masyarakat dimana diantaranya merupakan konsumen yang mempunyai tingkat loyalitas yang tinggi; IKM dapat mengembangkan produknya untuk menyentuh kalangan tertentu; menjaga kedisiplinan agar tetap ontime dalam memasarkan produknya; meningkatkan legalitas produknya ke tahap BPOM; menambah jumlah produksinya; menjalin komunikasi dalam rangka mempererat kerjasama dengan para distributornya; serta mengganti atau menambah mesin produksi agar lebih produktif. 
Berdasarkan penyusunan strategi di atas, maka dibuatlah marketing mix untuk IKM Ayudy tersebut. Dimana strategi produk yang direncanakan adalah mengembangkan varian produk baik dari segi rasa, ukuran dan kemasan serta membuat produk inovatif; strategi harga yang direncanakan adalah menciptakan produk baru dengan berbagai macam harga serta memberikan harga grosir untuk para distributor; strategi lokasi yang direncanakan adalah membuka gerai khusus untuk penjualan yang lokasinya dekat dengan pangsa pasar serta merambah lokasi pasar digital agar konsumen dapat memesan produk via online; dan strategi promosi yang direncanakan adalah menambah akun media social untuk memasarkan produk secara massif serta bergabung dengan e-commerce ternama dan sudah dikenal oleh banyak kaum milenial

\section{DAFTAR PUSTAKA}

Abidin, Moh Zainal., Mas'udin, Ilyas dan Utama, Dana Marsetya. 2017. Pemilihan strategi pemasaran dengan metode SWOT dan TOPSIS. Jurnal teknik industry vol 18 no 1 Februari 2017 pp : 55-67. p-SSN : 1978-1431 dan e-ISSN : 2527-4112

Amalia, Aisyah. 2016. Perencanaan strategi pemasaran dengan pendekatan bauran pemasaran dan SWOT pada perusahaan Popsy Tubby. PERFORMA : Jurnal manajemen dan star-up vol 1 no 3 Agustus 2016

Anggraeni, Shanti Kirana., Maarif, Mohammad Syamsul., Sukardi., Raharja, Sapta. 2017. Strategi peningkatan daya saing usaha kecil menengah berbasis olahan ikan di Indonesia : suatu tinjauan. Journal industrial service vol 3c no 1 Oktober 2017

Dalfa, Salisa., Ratih, Tresnati dan Srisusilawati, Popon. 2018. Kajian bauran pemasaran pembiayaan KPR Islamic banking menggunakan analisis SWOT (studi kasus pada BPRS Al Salaam cabang Bandung). Prosiding hukum ekonomi syariah vol 4 no 4 tahun 2018. ISSN : 2460-2159

Galavan, R. 2014. Doing business strategy. Ireland : NuBooks

Kotler, P dan Amstrong, G. 2012. Manajemen pemasaran. Bandung : Alfabeta

Kotler, P dan Keller, L. 2012. Marketing communication. Jakarta : Erlangga

Kuncoro, M. 2013. Metode riset untuk bisnis dan ekonomi. Jakarta : Salemba empat

Purwanti, Endang. 2012. Pengaruh karakteristik wirausaha, modal usaha dan strategi pemasaran terhadap perkembangan UMKM di Desa Dayaan dan Kalilondo Salatiga. Jurnal Among Makarti vol 5 no 9 Juli 2012

Ramadhan, A dan Sofiyah, FR. 2013. Analisis SWOT sebagai landasan dalam menentukan strategi pemasaran (studi Mc. Donald's ring road). Jurnal media informasi manajemen

Rangkuti, F. 2014. Analisis SWOT : teknik membedah kasus bisnis. Jakarta : PT. Gramedia pustaka utama

Saputro, JW., Handayani, Putu Wuri., Hidayanto, Achmad Nizar., Budi, Indra. 2010. Peta rencana riset enterprise resource planning dengan fokus riset pada UMKM di Indonesia. Journal of information system vol 6 no 2 pp : 140-145

Srisusilawati, Popon. 2017. Kajian komunikasi pemasaran terpadu dalam mendorong keputusan pembelian jasa perbankan. Jurnal Amwaluna vol 12 no 1 tahun 2017 
Sudaryanto. 2011. The need for ICT education for manager or agribusinessman to increasing farm income : study of factor influences on computer adoption in East Java farm agribusiness. International journal of education and development, JEDICT vol 7 no 1 pp : 56-67

Sudaryanto., Ragimun dan Wijayanti, Rahma Rina. 2013. Strategi pemberdayaan UMKM menghadapi pasar bebas ASEAN. www.kemenkeu.go.id/sites/default/ 31 Agustus 2015

Sugiyono. 2013. Metode penelitian pendidikan. Bandung : Alfabeta

Sugiyono. 2014. Metode penelitian manajemen edisi ke-14. Bandung : Alfabeta

Tjahjono, A dan Brahmana. 2013. Analisis marketing mix, lingkungan social, psikologi terhadap keputusan pembelian online pakaian wanita. petra : Jurnal manajemen pemasaran vol 1 no 2 pp : 1-9

Umar, Zainal Abidin. 2012. Strategi bauran pemasaran dalam meningkatkan volume penjualan ikan tuna olahan pada PT. Betel Citra Seyan Gorontalo. Jurnal INOVASI vol 9 no 1 Maret 2012. ISSN : 1693-9034

https://se2016.bps.go.id/umkumb/

https://www.kemenkeu.go.id/sites/default/files/strategi\%20pemberdayaan\%20umkm.pdf 